\title{
Las lecciones de los lectores. A propósito de la recepción literaria'
}

\author{
Readers' readings. On the subject of literary reception
}

\author{
VANINAPAPALINI \\ Universidad Nacional de Córdoba \\ Argentina \\ vaninapapalini@gmail.com
}

Resumen. En este artículo, propongo revisar las premisas y los modelos teóricos que abordan los procesos de recepción literaria. Con el interés de revisar aquellos caminos que resultaron poco conducentes en la investigación de la lectura, intento desmontar una serie de prejuicios que, de manera implícita, la condicionan y planteo una serie de interrogantes y cuestionamientos que tiendan a su superación. Sobre esta base, ensayo una reconceptualización de la lectura orientada a incorporar la dimensión subjetiva, un aspecto poco atendido en estos estudios. Mi hipótesis es que cualquier lectura puede instalar un diálogo subjetivo capaz de producir una transformación personal y que esta posibilidad no depende tiránicamente de la obra sino también del lector y de la manera en la se produce el encuentro con el texto. Finalmente, propongo una secuencia de ejes de entrevista que aspira a hacer emerger los procesos subjetivos articulados por la lectura.

\section{Palabras clave: lectores; lecturas; recepción} literaria; sociología de la lectura; subjetividad.
Abstract. In this article, I propose to review the assumptions and theoretical models that address the processes of literary reception. Reviewing those approaches to reading research that result less productive, I attempt to delineate a number of prejudices that implicitly condition it, and pose a series of questions designed to overcome them. On this basis, I trial a reconceptualization of reading oriented towards incorporating the subjective dimension, a neglected aspect of those studies. My hypothesis is that any reading can set up a subjective dialogue capable of producing personal transformation, and that this possibility depends not tyrannically on the work, but also on the reader and the way in which the text is approached. Finally, I propose a sequence of interview dimensions that aim to bring out the subjective processes articulated by reading.

Key words: readers; readings; literary reception; sociology of reading; subjectivity.

\footnotetext{
I Para citar este artículo: Papalini, Vanina (20I2). Las lecciones de los lectores. A propósito de la recepción literaria. Álabe 6 . [www.revistaalabe.com]

(Recibido 2I-OI-2OI2; aceptado O2-IO-2OI2)
} 
¿Se le ocurriría a alguien promover el amor? ¿Y encargar el tema a las empresas y los Estados?

(Petit, 200I, p. 23)

La promoción de la lectura es, desde la Ilustración, sede de obstinadas batallas político-ideológicas. Los motivos son diversos, pero en general convergen en establecer su valor para la adquisición de autonomía personal. La relación cultura letrada - juicio crítico - libertad, que abreva en la filosofía del Iluminismo y alcanza una expresión paradigmática en el texto de Immanuel Kant “Respuesta a la pregunta: ¿Qué es la Ilustración?”, no es privativa del liberalismo político sino que se extiende a las posiciones marxistas y anarquistas. Por eso, tanto los ideólogos y políticos conservadores como los intelectuales y militantes revolucionarios participaron del entusiasmo por fundar bibliotecas populares, un fenómeno que se extendió desde mediados del siglo XIX a mediados del XX y que fue emblema de la generalidad alcanzada por esta convicción.

Los argumentos en torno a la importancia de la lectura se despliegan y multiplican: para algunos, es un vector ineludible de la formación del ciudadano-soberano; para otros, es el baluarte de toda unificación cultural nacional (Kalman, 2008: пІо-ІІ3). Por cualquiera de estas dos vías, la lectura es concebida como fundamento y eje de la instrucción mínima obligatoria. Históricamente, los estados democráticos y las tiranías ilustradas tomaron como una responsabilidad inherente a sus funciones el estímulo de la lectura, que se opondría a una pereza lectora innata en los seres humanos. En la cuna del Iluminismo, Francia, existe una preocupación especial por el desarrollo de esta práctica, que no se limita a la enseñanza de la lectoescritura. La sociología de la lectura francesa ha acuñando un término que apunta a distinguir con fineza la alfabetización del "iletrismo" esto es, la adquisición incompleta o la pérdida parcial de las competencias de lectura y escritura, evidentes sobre todo en cuanto a la comprensión del sentido de un texto.

La sospecha de iletrismo y el acoso del fantasma no totalmente desterrado del analfabetismo ha llevado a la medición sistemática de la lectura, convirtiéndola en un tema de investigación recurrente para los gobiernos, para los cuales representa un problema atinente a la educación y, ocasionalmente, a la cultura. Se presume, según los resultados que arrojan periódicamente las investigaciones, que las poblaciones no alcanzan los niveles de lectura expectables.

En el afán de promover la lectura, los intereses de los estados y sus ministerios de educación coinciden con los de las cámaras de libreros y editores, para quienes la difusión del libro tiene una motivación económica. Cualquiera que sea el actor que impulse la investigación, las conclusiones suelen ser igualmente alarmantes: se constata con aflic-

\footnotetext{
${ }^{2}$ Neologismo proveniente del francés, creado en r98I por el Movimiento ATD Quart Monde, una organización internacional de lucha contra la pobreza y la exclusión social.
} 
ción que se lee poco, prefiriéndose el entretenimiento liviano a la lectura. Se presumen graves consecuencias de la apatía lectora: el empobrecimiento del vocabulario, el empeoramiento de la ortografía, crisis de la comprensión lectora y la redacción. El diagnóstico parece evidente: se lee poco, se lee mal. Y lo que se lee, no es valioso.

Estos estudios no sólo aseguran que se lee menos, sino que el libro, objeto-insignia de la cultura letrada, está amenazado y en peligro de extinción. Las nuevas generaciones están fascinadas por los videojuegos e internet - un medio cuya textualidad sería dudosa- como antes lo fueron por la televisión, la radio, el cine. El libro se virtualiza y se desvanece y, con él, la cultura corre el riesgo de su extinción.

Acorralados por todos los flancos, lectores y lectoras, débiles o contumaces, estacionales o constantes, deben admitir que no están a la altura de las ilusiones letradas. Me atrevería a decir que ni siquiera los estudiantes de las carreras de Literatura o Letras logran satisfacer completamente estas expectativas, puesto que no siempre leen obras completas sino que se limitan a seleccionar capítulos, movidos por el interés -esencialmente instrumental- de adquirir conocimientos y aprobar exámenes.

Vale la pena preguntarse si esta inclinación por la lectura es, efectivamente, un "mandato social" actual, es decir, si nuestras sociedades le asignan un valor primordial, erigiendo la erudición como un mérito. Mi impresión es que, a pesar de la tenue persistencia de algunos ideales de la Ilustración, quienes sostienen hoy la importancia de la lectura encuentran poca resonancia en el conjunto. Fuera del sistema educativo, que sigue siendo por ahora esencialmente moderno ${ }^{3}$, la promoción de la lectura es percibida como un precepto ajeno, forzado y quizá hasta anacrónico, desvinculado de las exigencias de la vida contemporánea; un lustre innecesario en una cultura políticamente pragmática y económicamente productivista.

Esto no significa que la lectura sea una práctica en desuso ni que, quien lee poco u ocasionalmente, o quien prefiere obras de éxito comercial a los grandes clásicos, no encuentre en ella algo que lo conmueva singularmente. Pero se trata de una práctica otra, que se ha reconfigurado casi completamente y que está lejos de ocupar el papel que se le asignó hasta I950 aproximadamente en la escena ciudadana. Estas transformaciones son las que sacuden el terreno de la investigación y obligan a examinarla bajo otras premisas. Mi tesis es que una lectura, cualquier lectura, puede instalar un diálogo capaz de producir una transformación personal. Eso depende no sólo de la obra sino también y acaso fundamentalmente, de los lectores y lectoras y de la manera en la se produce el encuentro con el texto. Esta aserción, que no es novedosa, asume un carácter escabroso en cuanto intentamos definir qué es "el lector": ¿es un conjunto de operaciones cognitivas?, ¿es un pathos afectivo?, ¿es una construcción social?, ¿es una biografía?, ¿es un anudamiento de culturas y condicionamientos que lo preceden y exceden?, ¿es un individuo con capa-

\footnotetext{
${ }^{3}$ Lentamente, los cambios en el currículo escolar van mostrando la desaparición de materias tales como filosofía, literatura e historia antigua, reemplazados por gestión de la producción, tecnología y administración, dando cuenta de una reconfiguración cultural e ideológica que se aleja rápidamente de los ideales de la Ilustración.
} 
cidad de decisión y acción?, ¿es un sujeto generizado, lectores y lectoras?, ¿ es un sujeto del aprendizaje, un niño o una niña, un joven o una joven?

Si bien no creo que la recepción dependa sólo de la obra, está condicionada también por la obra, vale decir: la obra cuenta. Ella invita, sacude, interpela, es capaz de producir sentidos -si hay alguien capaz de encontrarlos-, en mayor o menor medida dependiendo de su factura. A la inversa, también existe la posibilidad de que alguien encuentre ese plus en una obra que, según el análisis de la teoría literaria, no ofrece gran cosa.

En este artículo, hablaré indistintamente de "recepción de textos" y de "recepción literaria”, englobando la totalidad de lo escrito cualquiera que sea su soporte material, sin ingresar por ahora a la discusión sobre la definición de literatura. Algo de este debate se desarrollará más adelante. En primer lugar, me propongo cuestionar algunas aseveraciones de sentido común objetando un conjunto de sentencias simples muy divulgadas. A partir de este zócalo -compuesto de reparos más que afirmaciones-, quisiera proponer una conceptualización de la lectura que introduzca la dimensión subjetiva, un aspecto no comprendido en las investigaciones más frecuentes de este tema, cuya importancia surge con claridad en el relato de las experiencias de lectura narradas por algunas personas que aceptaron convertirse en "casos” de investigación. Para finalizar, intentaré delinear un corolario a la vez metodológico y conceptual que sirva a la investigación de quienes se dedican a la recepción literaria.

\section{Prejuicio cuantitativo: Leer es una práctica en desuso}

"Se lee menos que antes", asevera el Sentido Común. La alusión a un pasado dorado es, como todo mito, una evocación imprecisa que construye un momento ideal en el cual la lectura habría sido una práctica frecuente y ordinaria. Es imposible saber a qué época se refiere esta afirmación. ¿Al siglo XVIII consagrado por Habermas como el momento en el que emerge la opinión pública al calor de los debates en los cafés literarios? (Habermas, I98I). Esa recreación histórica es crucial porque apunta a revelar un modo de construir la democracia a través de instancias de interacción comunicativa, argumentación y razonamiento en común. Sirve de modelo ejemplar, a condición de abstraer las restricciones que, en su momento, experimentó esta práctica: la exclusión de las mujeres de los espacios públicos de lectura y discusión -aunque ellas sin dudas ejercían estas acciones, en cuanto se podía, en la clandestinidad- y de los niños y jóvenes, a la sazón fuera de la alfabetización obligatoria.

Según testimonia Alberto Manguel, “a comienzos del siglo XIX, cuando en Gran Bretaña todavía se rechazaba la idea de una mujer erudita, escuchar un texto leído se convirtió en una de las maneras de estudiar socialmente aceptadas" (2005: I34). Las lecturas compartidas, lejos de establecerse bajo una lógica comunitaria e igualitarista, suponían un control patriarcal: los textos debían ser los adecuados para la oyente, que aceptaba su jerarquía inferior frente al poder masculino. Desoír estas recomendaciones y elegir los libros a leer suponía una suerte de libertinaje intelectual inaceptable. 
El proceso rescatado y revalorizado por Habermas tiene importancia cualitativa, como ejemplo de un modo de ejercer la participación política, y no cuantitativa, como una época en la que "todos leían". Actualmente, y hablando estrictamente de magnitudes, el mercado editorial no se ha reducido; por el contrario, se amplió. El público lector en lengua española está compuesto por unos 400 millones de personas. No es ésta una cifra pequeña. Si existe una disminución de la lectura, ello no parece traducirse en las ventas de libros (BearingPoint-Esade, 2003).

En Francia, el debate sobre la significación de los datos estadísticos sobre la lectura está lejos de concluir. Para algunos, como Joëlle Balhoul (20O2), la importancia del grupo de los que leen poco ( a 9 libros por año) creció significativamente, mientras que descendió el porcentaje de los no lectores. Para Oliver Donnat, en cambio, existe una disminución en el ritmo de lectura, que se debe a una sobreevaluación de las declaraciones registradas anteriormente y al sesgo de las encuestas (2004: 67-68). Por su parte, Baudelot, Cartier y Détrez afirman que la práctica se vulgarizó y desacralizó: existe una mutación del modelo de lectura que es necesario atender (Poulain, 2004: 43). Además, la mayoría de los autores sostienen la necesidad de revisar todas las tipologías y conceptos, por ejemplo: si leer 9 o menos libros al año debe ser considerado un nivel de lectura insuficiente; cómo debe interrogarse a los entrevistados para que la enumeración de todos los libros leídos no restrinja las respuestas a la literatura considerada "legítima"; cómo establecer el impacto de la lectura producida en internet, etc. Determinar si la lectura es una práctica en decadencia depende también de poder conocer qué y cómo se lee y qué es lo que significa la pregunta ¿cuánto leyó usted en el último año?

\section{Prejuicio cualitativo: "Leer" es acceder a la gran literatura}

La lectura es una práctica valorada en relación con la calidad de los textos leídos. Como en toda ponderación cualitativa, la pregunta es quiénes determinan su valor. Los sistemas educativos, los críticos literarios, los columnistas de los medios masivos, los lectores expertos, los editores y hasta el público, son actores que, en distintos ámbitos y circunstancias, pueden realizar este ejercicio de validación o exclusión. Normalmente, el establecimiento del canon tiene que ver con lo que deciden especialistas y académicos; sus apreciaciones, que retroalimentan el sistema educativo, establecen un número variable de obras que merecen ser llamadas "literatura". Se sobreentiende que la lectura es una práctica desarrollada respecto de una obra literaria. Pero, así definida, sólo abarca a las lecturas "legítimas" (Bourdieu, I988).

Ciertamente, definir qué es la literatura es un problema sin respuesta final (Eagleton, I998). En este sentido, ningún juicio puede ser universal ni imparcial, al contrario, es motivo de numerosas controversias. En cada tiempo histórico gravitan tradiciones y concepciones que responden a esta pregunta de manera distinta. Aún bajo sospecha, y de maneras difusas, en cada época y sociedad puede reconocerse un canon literario que establece el acervo de obras y autores considerados "literatura” en función de la calidad y 
el género de los escritos: ensayo, cuento, novela, poesía, teatro, entre otros, ingresan en esta clasificación. En un segundo nivel se ubican las formas literarias menores: libros periodísticos o de divulgación, libros de humor, historietas, libros de frases o misceláneos, novelas rosa, folletines y los llamados best-sellers, es decir, literatura con fines comerciales. Excluidos de la definición de literatura se ubican los denominados libros "prácticos", técnicos, profesionales, de autoayuda, de cocina y manuales de distinto tipo. Existen otros tipos de lectura, como las publicaciones periódicas, generales o especializadas, los semanarios, la prensa... En los contornos de cualquier delimitación, se emplaza un cierto número de obras desjerarquizadas, ilegítimas o de valor incierto, desclasificadas del territorio literario. Consecuentemente, fuera del círculo áureo del canon, no sólo la clasificación de la literatura se vuelve dudosa; también la práctica de la lectura es puesta en cuestión.

Una definición del término "literatura" en un diccionario engloba a las obras con una intención estética, capaces de generar un deleite específico. Los lectores serían, así, los que leen movidos por la búsqueda de un goce elevado, promovido por la calidad artística de la obra. La distracción, o la finalidad instrumental -que va desde la resolución de un problema a la adquisición de conocimientos- no son motivaciones inherentes al goce literario.

Desde este punto de vista, la definición queda del lado de la recepción: una obra literaria que es leída con el interés de aprender la lengua, no constituiría "literatura” y, a la inversa, una lectura inspirada podría encontrar poesía en una receta de cocina. No obstante, de manera implícita o explícita, los lectores y, en ocasiones, los investigadores entienden literatura por "bellas letras".

El canon incluye y excluye no sólo obras sino también autores. Estos procedimientos son complicados y plantean más de una duda. Por ejemplo: con la admisión de Paulo Coelho en la Academia de Letras de Brasil, ¿cambia el estatuto de El alquimista y del resto de su obra? Los expertos que establecen estos parámetros son sensibles a las presiones y juegos de poder de su tiempo, están influidos por las ideas y valores, tendencias y tradiciones de su época y sus juicios no pueden sustraerse a estos encuadres.

La práctica de lectura, sin embargo, no depende de estas consideraciones. Ginzburg relata magistralmente, en El queso y los gusanos (I98I), los profundos efectos de sentido y de representaciones de mundo que llevaron a un molinero del Friuli a establecer su propia teoría de la creación del mundo. Las lecturas "vulgares" de Menocchio -folletines, evangelios apócrifos, publicaciones clandestinas de sectas no ortodoxas- configuraron una experiencia única que, afortunadamente para los estudios de la recepción, quedó plasmada en los juicios inquisitoriales y fue recogida por el historiador italiano. Un ejercicio que ayudaría a comprender la producción de la legitimidad cultural de nuestro tiempo sería averiguar quiénes son los inquisidores del siglo XXI y en nombre de qué dogma encumbran y descartan textos.

Si la lectura es una práctica compleja y de ricas resonancias subjetivas, no parece suficiente establecer el valor de la obra para juzgar la trascendencia de la práctica. En los 
confines de las bellas letras, emergen las literaturas populares y los textos paraliterarios, capaces de proveer a la cultura de figuras míticas como James Bond y Tarzán, que sintetizan representaciones sociales y movilizan resortes psíquicos profundos (Boyer, 2008).

La significación de la lectura trasciende el valor de la obra literaria. La cultura contemporánea no puede prescindir de los superhéroes de historieta sin perder una parte fundamental de sí. ¿Acaso podría comprenderse el mito del self-made man de mediados del siglo XX -que abonó la creencia social del ascenso individual- sin la divulgación de las biografías de los grandes inventores, empresarios y emprendedores, divulgada en folletines o en el célebre Readers' Digest?

\section{Prejuicio generacional: Los jóvenes no leen}

La presunción de que se lee menos en general, y entre los jóvenes en particular, suele encontrar asidero en la multiplicación de opciones de actividades de tiempo libre que crecieron exponencialmente desde i950. No se trata sólo del cine y la televisión; hacia r990 se suman los deportes y el fitness, el turismo, los espectáculos musicales, los clubes de aficionados, los juegos en red, las redes sociales y comunidades virtuales en Internet, los bailes -que, en diferentes segmentos horarios, ya alcanzan a los niños desde los 9 años-, y un extenso número de prácticas diversas que resultaría improbable resumir aquí y que no atañen únicamente a los jóvenes.

Como actividad recreativa, el libro tiene fuerte competencia. Y con todo, no le va mal. Los recientes grandes éxitos de la literatura infantil y juvenil, como la saga de Harry Potter y la serie de los vampiros adolescentes iniciada por Crepúsculo, atestiguan un renovado interés por la literatura que se retroalimenta en su relación con el cine. Las películas más vistas y los libros más comprados guardan una complementariedad evidente (Papalini, 2OIO).

Según publicó la Agencia Reuters, las ventas en todo el mundo de los primeros cinco títulos de Harry Potter rompieron todos los récords, superando los 250 millones de dólares. Los libros se tradujeron en más de 6o idiomas y se distribuyeron en alrededor de 200 países. Un fenómeno parecido, muy significativo aunque con menor impacto en las ventas, aconteció con la trilogía de El señor de los anillos, de J. R. Tolkien, orientada a un público algo mayor y más amplio, pues también los adultos fueron capturados por las historias. Entre los adolescentes, la saga de Stephenie Meyer genera una atracción magnética semejante a la de Harry Potter, al punto de reservar los libros antes de que estén disponibles en el mercado editorial.

Si ampliamos el espectro de lo que se considera "lectura", tenemos que considerar un cúmulo de textos diversos que estos públicos frecuentan: semanarios y revistas orientadas a jóvenes o a niños, revistas vinculadas con series televisivas o estrellas de la música, revistas de historietas y un sinnúmero de textos en formato virtual.

Entre los niños más pequeños, el libro se introduce tempranamente, adquiriendo una 
forma semejante a un juguete: los nuevos libros infantiles incorporan elementos que sensibilizan otros sentidos, además del visual: el tacto, por ejemplo, incentivado por la presencia de materiales diversos, y el oído, estimulado por sonidos o fragmentos musicales. Además, estos libros infantiles se esfuerzan por romper la bidimensión tradicional, desplegándose en el espacio real. A partir del año, el libro puede formar parte del universo infantil.

El segmento infanto-juvenil representa un porcentaje importante de las ediciones y goza de gran vitalidad, más allá de las lecturas obligatorias a las que los niños y jóvenes escolarizados están obligados por el sistema educativo. Hasta podría parecer que muchos jóvenes leen más, y no menos, que los adultos...

\section{Prejuicio ilustrado: Leer es una práctica emancipatoria}

A pesar de su ya antiguo afianzamiento, afirmar que "el libro nos hace libres" es riesgoso y poco demostrable. El cliché expresa una síntesis filosófica -con beneficios mercantiles colaterales- de los principios ilustrados, estableciendo un lazo fuerte entre la autonomía y la cultura que es fundante de la modernidad. Para los pensadores iluministas, el ejercicio claro de la razón combatiría la ignorancia, la superstición y la sujeción a la tiranía, a fin de construir así "el mejor de los mundos posibles". Las Luces se impondrían por una doble vía: el progreso conduciría a la felicidad; la educación, a la libertad.

La relación entre el raciocinio y la autonomía está mediada por la ilustración, entendida como una formación erudita, libresca, originalmente no regulada por un sistema educativo cuya invención es posterior. De hecho, se trata de abandonar las tutelas, especialmente las ejercidas por las instituciones religiosas y las tiranías políticas.

"La minoría de edad -dice Kant en I784- estriba en la incapacidad de servirse del propio entendimiento, sin la dirección de otro." Alcanzar la mayoría de edad, la autonomía, implica la valentía de pensar por uno mismo. Más adelante, el filósofo precisa: “entiendo por uso público de la propia razón el que alguien hace de ella, en cuanto docto, y ante la totalidad del público del mundo de lectores" (I992: 59). El ejercicio del juicio crítico emerge en los lectores y se consolida en la discusión con otros letrados.

La referencia primigenia de esta relación resulta extemporánea y es necesario recuperar la concreción de sus condiciones históricas. ¿Qué tipo de formación libresca es ésa que se postula? Si hubiera que indicar el libro por antonomasia, el hijo dilecto del Iluminismo es la Encyclopédie. ¿Se trata, entonces, de la incorporación de información? No parece ser ése el espíritu de la reflexión kantiana. Si así fuera, deberíamos haber alcanzado un grado máximo de emancipación: nunca antes hubo tanta información disponible como hoy, a través de internet. Y sin embargo, lejos de significar libertad, la proliferación de datos fragmentarios -como los de una enciclopedia- está causando una suerte de asfixia intelectual. 
El mero acopio no implica el establecimiento de un juicio crítico; la actividad de la razón supone fundamentalmente la reflexión; para esto, el libro -y la discusión- no son más que un medio, un estímulo. Lo fundamental son los procesos que desencadenan. En este sentido, es importante destacar que, para Kant, la erudición individual es completada por el debate público, componiendo un orden más democrático basado en un conjunto de decisiones intersubjetivas.

La relación entre lectura y reflexividad, y entre lectura y emancipación, no es lineal ni mecánica sino que involucra el desentrañamiento de intrincados procesos subjetivos. Toda correspondencia directa entre uno y otro término es fácilmente rebatible: aunque puede verificarse que la educación y su herramienta, el libro, han alcanzado a gran parte de la población del mundo, no parece que haya aumentado de manera correlativa el pensamiento libre y la reflexión crítica, aunque evidentemente, aún nadie afrontó la improbable tarea de medir socialmente sus niveles.

Como señala Martine Poulaine "la difusión de la lectura es, a pesar de las lagunas y de las carencias, un hecho consumado, y es evidente que esto no es sinónimo necesario e inmediato de la emancipación" (2004: 49). Me atrevo a decir que el artefacto "libro" es un engranaje de un dispositivo más complejo: resulta insuficiente examinar el texto, hipotetizando sobre su función, para comprender la dirección en la que se despliega la máquina de lectura, de la cual lector y libro constituyen sólo sus aristas visibles. Quizá, entonces, ni la lectura ni la información sean condiciones necesarias y suficientes de la autonomía -término que, ciertamente, reclama una fuerte problematización-, pues aún en su sentido moderno, esta no se realiza exclusivamente en la dimensión personal ni como efecto directo de la incorporación de saberes.

\section{Prejuicio tecnofóbico: Internet no es lectura}

$\mathrm{Si}$, como asevera Roger Chartier, leer es una práctica que se ejerce frente a textos (I999: 200), el libro es un soporte más entre otras alternativas. Se admite sin discusiones que la escritura realizada sobre papiros, madera o piedra puede ser leída, pero, si se trata de una pantalla, aparece una fuerte resistencia y un sinnúmero de objeciones.

El gesto de desconfianza reconoce un eco lejano: hasta hace poco, las pantallas eran medios al servicio del entretenimiento -y no de la "cultura", entendida en sintonía con las "bellas artes”: la televisión coronó y fijó el sentido del proceso controversial iniciado por el cine; posteriormente, la aparición de los videojuegos fue una derivación previsible de su función conocida.

Con todo, las pantallas van ganando legitimidad. A pesar de la nostalgia por el papel y la tinta, el libro electrónico tiende a ser aceptado, constituyendo un exponente acabado de sincretismo epocal: con algunas concesiones nostálgicas, como la ilusión de pasar las páginas, es una unidad de memoria capaz de guardar cientos de textos. 
El problema mayor se plantea con esa plataforma caleidoscópica llamada internet. Allí conviven las conversaciones banales, el correo, el álbum de fotos, las páginas personales exhibidas para el comentario y la intervención del grupo social de pertenencia, enciclopedias y diccionarios, datos sueltos de todo tipo, artículos y revistas científicas, juegos, imágenes pornográficas, música, películas, radio y televisión.

Es innegable que en internet se lee, sólo que se trata de otra representación textual. Allí la lectura exige una postura corporal distinta, una exigencia visual que va variando según cambia la tecnología y probablemente, un grado de atención diferente. Aún no se sabe si este modo de acercarse al texto desencadena otras maneras de pensar u otros procesos intelectuales; hay numerosas teorías al respecto (Litwin, 2005), pero sin un juicio concluyente.

Para Umberto Eco, este registro es inseguro y se corre el riesgo de perderlo todo: "La hoja nos da garantías, mientras que el soporte electrónico no. Basta que haya una desmagnetización general o que un empleado se olvide de digitalizar los contenidos de nuestros bancos de datos y quedamos todos alzheimerizados" (2010: 4).

La preocupación de Eco por el libro en papel como un modo más seguro de conservación del pensamiento no se traduce en argumentos demasiado convincentes. A pesar de la aparente mayor estabilidad del documento escrito o impreso, son pocos los libros de la Antigüedad clásica que resistieron hasta nuestros días. Hay accidentes posibles, incendios, inundaciones y otros desastres naturales capaces de devastar bibliotecas completas. Existen también guerras, en las que se destruye sin escrúpulo alguno el patrimonio cultural de la humanidad. No son las guerras de un pasado superado, ni ejércitos de talibanes logoclastas: recordemos que en febrero de 2005, soldados norteamericanos saquearon y destruyeron archivos, bibliotecas y museos de Irak.

La reivindicación del libro en papel, si es que amerita una defensa, debería involucrar otras cuestiones. La relación entre lectura escrita y conceptualización ha sido largamente estudiada. Internet, en cambio, presenta una modalidad de lectura diferente, y falta mucho todavía para poder establecer qué tipos de cognición desencadena.

En mi opinión, el peligro de desaparición, extinción u olvido está siempre latente. Los registros de la cultura peligran, fundamentalmente, cuando la primera sede de preservación y valoración, la lábil memoria humana, no puede, o no quiere recordar; no puede, o no quiere hacer de esos contenidos objeto del pensamiento. Por ahora, las alarmas sobre el médium son sólo sospechas que sirven de fermento para nuevas investigaciones.

\section{Los prejuicios anti-intelectuales}

Existen muchos más prejuicios de los que es posible tratar aquí. Reseñaré brevemente algunos que operan principalmente en los contextos de los receptores:

a) La pasividad de la lectura contra la actividad laboral: Para muchas personas, la lectura es una pérdida de tiempo. Quien lee, no puede hacer. En las biografías 
de lectura que hemos relevado, son muchos los casos en los que se relata que, durante la infancia, eran llamados por los padres o adultos repetidamente para que realizaran alguna tarea. El joven lector pasaba entonces a una suerte de clandestinidad, ocultándose para poder continuar enfrascado en su libro. Cuanto mayor es la exigencia de ocupación en un trabajo o tarea, menos conveniente resulta la lectura. En las familias exigidas por la necesidad de aportar a la economía doméstica, la lectura se convierte en una práctica individualista inaceptable, puesto que perjudica al conjunto. Leer es, en estos casos, un privilegio, pero también es una sustracción de los imperativos externos y la configuración de un espacio propio. Estos "lectores de closet" muchas veces construyeron trayectorias de vida originales, que no reproducen el habitus familiar y social en el que fueron educa$\operatorname{dos}^{4}$.

b) En el otro extremo de la cadena social, el tiempo es oro en el sentido de la producción de riqueza, no ya de la urgencia por cubrir las necesidades básicas. Quizá en la infancia y la juventud existan mayores permisos, e incluso estímulos, para la lectura. El revés se produce en la vida adulta. El tiempo de lectura podría ser tiempo productivo, Time is Money. En los puestos de trabajo donde se toman fuertes decisiones, existe muy poco tiempo disponible para la lectura. La información se presenta en resúmenes y compendios que sintetizan los elementos necesarios para la decisión. La lectura por placer se circunscribe a las vacaciones o a los momentos previos al sueño.

De este prejuicio se derivan algunos otros:

c) La "pasividad" -muscular- de la lectura contra la "actividad" del trabajo generaliza a esta práctica, asociando el primer atributo a lo masculino y el segundo a lo femenino. En ciertos círculos, se considera que leer es una actividad "de mujeres" -y de hombres de masculinidad dudosa-, mientras que cualquier labor físicamente exigente (el deporte, la velocidad, el sobretrabajo) son varoniles.

En muchos países, en particular en los medios populares existe una idea de que leer es algo que feminiza al lector. [...] La angustia de perder la virilidad es particularmente clara cuando el libro puede despertar el mundo interior, evocar una interioridad [...] Asimismo, la pasividad a inmovilidad, que la lectura parece requerir puede ser vivida como angustiante (Petit, 2004: 54-55).

d) El defecto devenido virtud: si los sectores de menores recursos no leen (no tienen tiempo para leer, o no se ha instalado ese hábito por una precaria inclusión en

\footnotetext{
4 Según la teoría de Pierre Bourdieu, los habitus constituyen estructuras sociales internalizadas, incorporadas al agente en forma de esquemas de percepción, pensamiento y acción. Estas estructuras están estructuradas por un conjunto de condiciones de existencia -ligadas a la clase social- que producen sistemas de disposiciones duraderas, capaces a su vez de funcionar como estructuras estructurantes, es decir, como pautas ordenadoras de prácticas y representaciones. En este sentido, los habitus tienden a la reproducción social (Bourdieu, I99I). Mi posición es que esta incorporación de habitus, que sufre modificaciones en el momento de interiorizarse, puede torsionarse más aún. Una actividad como la lectura supone un trabajo que moviliza instancias psíquicas profundas, pudiendo estimular un distanciamiento o una ruptura con las estructuras interiorizadas.
} 
el sistema educativo), es porque la lectura no es una práctica propia de los sectores populares. Los grupos políticos populistas se definen muchas veces como anti-intelectuales. Al revalorizar otras actividades que estos sectores efectúan, pueden llegar a denigrar lo que no realizan. Desde mi punto de vista, aún cuando una ilustración tramposa se convierta en una estrategia de poder de los sectores hegemónicos, ensalzar la ignorancia no parece ser una buena defensa.

e) La "acción” contra la "reflexión": en la misma línea de la pasividad-actividad, la oposición entre acción y reflexión esteriliza ambas prácticas. Se plantea que la reflexión plantea dudas, la acción es positiva; la reflexión inmoviliza, la acción transforma el mundo. Ahora bien, si la acción responde a un impulso no mediado por un razonamiento, puede volverse una reacción ciega; si no persigue un objetivo dictado por la reflexión, es inconducente, va a tontas y a locas, se desperdicia. La reflexión no es una suerte de ensimismamiento ausente del mundo sino un modo de pensarse en él, cuyas consecuencias se traducen en formas de habitarlo. En muchas ocasiones, a través del estudio se desarrollaron pensamientos y praxis revolucionarios. La lectura no es una maniobra evasiva.

\section{Otras vías para responder a la pregunta ¿qué es leer?}

Hasta aquí, he intentado socavar algunas premisas claves que subyacen en las investigaciones y políticas tendientes a la promoción de la lectura, introduciendo una dimensión que no es frecuentemente tratada ni por los sociólogos ni por investigadores del campo literario. Se trata de la subjetividad.

Entiendo por subjetividad la resultante heterogénea de las redes que constituyen lo social: son estas fuerzas contradictorias y en devenir permanente que actúan produciendo sujetos, objetos, condiciones de inteligibilidad, instituciones, sistemas de signos y relaciones sociales. Desde una perspectiva deleuziana (Deleuze \& Guattari, I977), podemos hacer ingresar esta dimensión a las investigaciones sobre las prácticas de lectura si las pensamos bajo la imagen de "máquinas lectoras" configuradas como articulaciones de múltiples elementos que no tienen ni una forma determinada ni un único curso de acción posible, siguiendo la premisa de que el sujeto-lector o sujeto-lectora no son un producto terminado, un artefacto descodificador que sigua una programación definida. Una máquina lectora acciona una potencia, es causa y efecto de múltiples líneas anudadas provisoriamente que se replican o se insubordinan a partir de allí.

La subjetividad no es una dimensión fácil de aprehender: sus matices sólo se perciben en una conversación profunda con los lectores. Petit lo explica de este modo:

Hay textos, o más bien fragmentos de textos, que funcionan como otros tantos insights, para tomar ese término de los psicoanalistas, como otros tantos haces de luz sobre una parte del sí mismo en sombras hasta ese momento. El texto viene a liberar algo que el lector llevaba en él, de manera silenciosa. Y a veces encuentra allí la energía, la fuerza para salir de un contexto en el que estaba bloqueado, para diferenciarse, para transportarse a otro lugar (Petit, 2004: 48). 
No toda lectura desencadena los mismos procesos, pero en ocasiones logra establecer un diálogo subjetivo que ayuda a la autotransformación y a la recreación identitaria. En mi opinión, leer es una práctica que tiene la capacidad de movilizar el registro imaginario y el simbólico (Lacan, I966), en direcciones no necesariamente coincidentes; al contrario: esta actividad puede ponerlos en contradicción, actuando como una matriz "suscitativa" o abierta a líneas de fuga que emergen, paradójicamente, de su propia celda.

Por un lado, los textos forman parte del universo simbólico objetivo: la sociedad y la cultura, replicadas y recreadas en los habitus en los que el lector es modelado: sistemas de signos, matrices de interpretación, parámetros de legitimidad, disposiciones del gusto y la sensibilidad, son configuradas dentro de los cauces hegemónicos. Las lecturas corresponden a este orden: en tanto emergen de la cultura y están marcadas por sus reglas, la reproducen parcialmente, aunque la recreen y "hagan trampas" a las fuerzas coercitivas de los códigos intentando ampliar los márgenes de la experiencia humana (Barthes, I982: II3-I22).

Por otro, existe una dimensión reflexiva, singular y propia, el registro imaginario, que tiene una dinámica subjetiva y personal, un espacio -un pliegue- con una dinámica única donde ese diálogo íntimo entre el libro y el sujeto puede hender una brecha, creando dentro de las estructuras interiorizadas una comarca insospechada, exclusivamente hollada por el lector. Si, en tanto queintroduce esquemas simbólicos, la cultura es una instancia performativa; la lectura -no el libro- puede reconfigurarla, siquiera momentáneamente, en una actividad en la que tanto pueden colaborar obra y lector, como ser patrimonio privativo de una apropiación "disidente" disparada por el texto5.

Este proceso no es equivalente al de la "recepción" vista como una actividad interpretativa: la apropiación se distingue de la recepción porque significa integrar a lo propio, es decir que actúa en un nivel profundo e inconsciente. Intento decir que la apropiación no es ni una introyección mecánica ni un juicio crítico; implica una refracción, esto es, una rarificación subjetiva: desviaciones, desplazamientos, morigeraciones, acentuaciones, efectos de la máquina de lectura.

Llamo "refracción” al proceso de interiorización modificada de lo leído, donde "lo dado" es recreado bajo la inspiración de "lo suscitado". El hecho objetivo, proveniente del afuera -el texto- se resitúa en el interior del sujeto a través del pliegue que produce la lectura, aconteciendo un proceso de subjetivación heteróclito. Al interiorizarse, se modifica: ocurre como si atravesara densidades diferentes. Su incorporación no debe entenderse como asimilación de un contenido puramente intelectual; tiene resonancias afectivas cuyos ecos en la vida del sujeto son asincrónicos.

En términos de la constitución de subjetividades, el universo simbólico brinda orientaciones y apremia, pero no impone: ofrece modelos de cómo ser, cómo pensar,

5 La recepción nunca se independiza totalmente del texto. Si la obra tiende a que el sujeto se adapte a sus condiciones de existencia - el caso frecuente de los libros de autoayuda- o a proporcionarle un momento de esparcimiento con recursos simples, es difícil -aunque no imposible- que se generen ideas o procesos de sentido complejos. 
cómo actuar, qué desear, es decir, proporciona pautas “convenientes”, adaptadas al orden existente, que reclaman una apropiación. Su estrategia es la de la naturalización y la persuasión, la de la cohesión y la continuidad.

Aunque los procesos de subjetivación responden en líneas generales a la lógica del poder instituido -plasmado en objetos, instituciones y condiciones-, requieren de sujetos singulares para su despliegue, configurados a su vez por procesos imperfectos e inacabados. De allí que la actividad de producción social de subjetividades -funcional a las sociedades y a los contradictorios intereses que las gobiernan- debe ser actualizada ininterrumpidamente. La subjetividad se constituye como campo de refracción y anclaje de las estructuras sociales, modificadas en el momento mismo en que se establecen como subjetivas.

La lectura puede tanto servir de horma como de punzón que ayude a horadar estas estructuras. Vista desde esta perspectiva, la relación lector-lectura es una relación dinámica y única, que sólo puede plantearse de forma general en función de un modelo analítico. Esta potencialidad, para nada automática ni garantida, es la que inspira la relación establecida, muchas veces de manera abusiva, entre lectura y autonomía. Pero también la inversa es cierta: la lectura puede servir de instrumento para una mejor adaptación, enmascarando los síntomas de los conflictos, proporcionando compensaciones, estimulando fantasías o ensoñaciones y divulgando argumentos legitimadores de un orden dado para que se perpetúe incuestionado.

Propongo repensar la lectura de manera tal que la subjetividad del lector ingrese palmariamente en la constelación de factores estudiados, desde este enfoque particular: la recepción literaria debe ser pensada como una instancia de refracción por la cual algunos haces penetran en la interioridad e irradian una nueva luz sobre zonas íntimas o redescubiertas de la experiencia vital del lector ${ }^{6}$.

\section{Estudiar la lectura}

Aunque todavía es prematuro procurar que los estudios de la lectura acometan la perspectiva de la subjetividad, las teorías de la recepción literaria han preparado el terreno. La hermenéutica, la crítica recepcional empírica, la estética de la recepción de la Escuela de Constanza y los estudios culturales han sido claves para la comprensión del lugar del receptor en la lectura (Acosta Gómez, I989). Por su lado, la sociología de la lectura y la sociología de la literatura aportaron su experticia para desentrañar qué significa la recepción en tanto que práctica (Lahire, 2004), mientras que los estudios de cultura

\footnotetext{
${ }^{6}$ La lectura, tanto como la escritura, constituyen “tecnologías del yo”, en los términos definidos por Foucault. Estas tecnologías "permiten a los individuos efectuar, solos o con ayuda de otros, cierto número de operaciones sobre su cuerpo y su alma, sus pensamientos, sus conductas, su manera de ser; es decir, transformarse con el fin de alcanzar cierto estado de felicidad, de pureza, de sabiduría, de perfección o de inmortalidad" (Foucault, I990: 48).
} 
escrita vinculados a la educación ofrecieron un panorama más amplio y matizado de la lectura en contextos de aprendizaje (Rockwell, I995), de intuiciones y saberes más o menos espontáneos (Fernández, 2006), o de exigencias existenciales (Kalman, 2003). No obstante, la dimensión de la subjetividad es una materia ajena a unos y a otros, puesto que implica un abordaje biográfico cercano a la psicología social y a la antropología.

Los diálogos interdisciplinares sobre este objeto de estudio común son todavía escasos y padecen de una cierta dificultad para incorporar articuladamente los textos y sus significaciones; el lector, su biografía y sus interpretaciones; las condiciones de circulación de los libros y las comunidades interpretativas o redes sociales de las que el lector forma parte. Hay una tendencia a que los investigadores que provienen del campo literario se concentren en los dos primeros nudos de la investigación (textos y lectores), con énfasis en las obras, mientras que los sociólogos desatienden justamente la intentio operis (Eco, I998), y la construcción de las significaciones en relación cruzada entre el texto y el mundo, con lo cual llegan a posiciones extremas: o bien los sentidos que emergen en recepción se independizan completamente de su motivo o bien son sobredeterminados por instancias sociales.

Creo necesario repensar la lectura como práctica e investigar en ella atendiendo a la multiplicidad de aspectos que la constituyen. El enfoque de la recepción que propugno intenta mantener un equilibrio entre el sentido literal, las resonancias e interpretaciones que concibe el lector y los marcos interpretativos que actúan sobre él, pensados como instancias interpersonales, sociales, culturales e históricas.

Mi interés es examinar estos diálogos entre textos y lectores sabiendo que ambos son hablados por otras voces. La aproximación que propongo intenta restituirlas, al menos parcialmente, como tramas sociales y biográficas. La trayectoria de lectura consiste, como señala Michel Peroni, en atender a la "no linealidad de las etapas sucesivas en la trayectoria de un lector, y también en la construcción situacional de un sentido de la lectura distinto al que comunica el modelo dominante" (2003: 30).

Si se admite la importancia de la dimensión subjetiva para comprender la significación de la práctica de la lectura que he tratado de sostener aquí, y con el propósito de superar los prejuicios que se identificaron precedentemente, es preciso esbozar un tipo de abordaje empírico que pueda resultar eficaz para ambas cuestiones. Evidentemente, como en toda ocasión en la que es necesario conocer el sentido de una práctica, la voz de los actores constituye la vía privilegiada. La entrevista, por lo tanto, aparece como la técnica de investigación más apropiada.

En nuestras investigaciones, la entrevista toma la forma de una conversación larga, poco estructurada, profunda, que intenta lograr cierto grado de asociación libre en las respuestas, facilitando de este modo la emergencia de la afectividad y los recorridos subjetivos. Por eso, no se utiliza un cuestionario sino que se identifican ejes sobre los cuales se interroga de manera abierta. El orden puede variar; se intenta seguir el discurrir de la charla realizando la menor cantidad de interrupciones posibles. 
Presentaré las distintas dimensiones de indagación, indicando también algunas referencias de los casos que hemos analizado y respetando la secuencia que utilizamos comúnmente:

a) Para construir una biografía de lectura, es fundamental la evocación de la infancia y la juventud y las prácticas de lectura propias y de la familia. Las connotaciones afectivas que acompañan la rememoración de esta etapa suelen ser fundamentales para comprender las trayectorias lectoras adultas. En nuestras entrevistas, hemos encontrado tanto una continuidad con los modelos de lectura parentales (la reproducción del habitus familiar), como una completa ruptura: el niño que se encierra para leer y se abstrae de las demandas familiares es un caso típico y frecuente. La posibilidad de recordar obras y autores significativos de este período y de vincularlo con acontecimientos significativos puede permitir un acceso clave a la subjetividad del lector. No obstante, no siempre esto es posible. Se recupera de la memoria un libro, su tapa, vagamente su contenido, a veces el autor y a veces el título y se sabe que fue importante, pero no se recuerda por qué. Iniciar una entrevista por un recorrido biográfico que comienza desde los primeros recuerdos suele instalar al entrevistado casi instantáneamente en un universo donde todos los objetos están investidos afectivamente y es una vía magnífica para encaminarse en una conversación más profunda, mientras que, si se comienza preguntando por las lecturas actuales, la charla adquiere un cariz más informativo y un registro netamente intelectual.

b) Es fundamental poder identificar los textos y los autores leídos, pero es aún más importante abordar la interpretación que el lector hace de las producciones que le resultan significativas. Este punto es uno de los menos frecuentes en la sociología de la lectura, y sin embargo es fundamental para comprender cómo se produce la refracción. Lo más difícil es reconocer cómo se construye la matriz interpretativa, pero en el decurso de la entrevista van emergiendo pistas que permiten alcanzar cierta comprensión de los procesos. Para el análisis, es imprescindible haber leído estos mismos textos señalados por el entrevistado y poder identificar las distancias con el sentido literal. Esta tarea implica, justamente, un ejercicio interdisciplinario en el que los investigadores provenientes del campo literario tienen mucho que decir a los sociólogos.

c) La existencia de una biblioteca personal, su composición actual y pasada y la forma en que los libros pasaron a formar parte de la biblioteca es uno de los aspectos clásicos a indagar en la entrevista. La diversidad de continentes y contenidos que suelen presentar sirven no sólo para ampliar el recorrido de los temas a tratar -aparecen libros insospechados- sino también como control de la información: se completan omisiones, se establece cierta correspondencia con lo dicho, etc.

d) Otro de los ejes de entrevista clásicos se refiere a las características concretas de la práctica de la lectura: la forma de leer (¿marca el texto?, ¿resume?, ¿extrae frases?), el modo de contacto con el texto (¿compra libros?, ¿le prestan?, ¿fotocopia?), el 
lugar y el momento de las lecturas, las motivaciones que lo llevan a leer, la finalidad de la lectura (¿trabajo?, ¿placer?, ¿usos prácticos?, ¿soledad?, ¿malestar?). En este momento es oportuno también indagar por otros consumos culturales asociados a la lectura, especialmente la relación con los medios masivos e internet.

e) Con el objetivo de captar las intertextualidades que el lector teje, es beneficioso preguntar por los metatextos (reseñas, críticas, comentarios en revistas o diarios, folletos de librerías o publicidades, menciones dentro de textos ya leídos, etc). Estos metatextos permiten identificar comunidades interpretativas: grupos de amigos, compañeros de alguna actividad especial o del trabajo, redes sociales generales y comunidades virtuales, por ejemplo. Existen otros informantes "expertos" que pesan en la elección e interpretación de una lectura, como los libreros, bibliotecarios y, si el entrevistado está en una etapa de estudio, las instituciones educativas o educadores específicos que dejan una huella afectiva. Identificar quiénes son las voces autorizadas es también relevante.

f) El encuentro con el libro, cómo llega este al lector o cómo es elegido, es un momento clave, que resulta más rico si puede ser narrado como una micro-rutina y en detalle. Recién aquí, y ya con un relato extenso previo, que permitió conocer a nuestro entrevistado y su vida en distintas situaciones, es posible realizar algunas abstracciones y pedirle que cuente cuáles son y han sido sus preferencias de género en distintas etapas de la vida. Si esta pregunta se ubica al principio, las lecturas menos legítimas no emergerán. Además, si el entrevistado construye una estructura de relato, le será necesario mantener una coherencia biográfica que implicará el cercenamiento de numerosos detalles ricos de su trayectoria en la lectura.

g) Hacia el final de la entrevista, pueden completarse datos más concretos y menos cualitativos, como la frecuencia y la estacionalidad de la lectura, los materiales que se lee habitualmente y los títulos leídos en el último año. Aquí también se pueden precisar datos que hacen a su contexto del mundo de la vida: familiares, sociales, educativos y culturales básicos.

Para finalizar, me gustaría hacer una recomendación: es crucial adentrarse en la entrevista con la mayor apertura y la menor cantidad de prejuicios posibles. Como nos ocurrió con el caso de Vicky, una profesora de arte de 72 años retirada y aficionada a los libros de autoayuda:

Mirá lo que estoy leyendo, porque es una cosa inaudita lo que estoy leyendo. Porque lo había empezado, me gustó, me gustó el libro porque es muy bueno, es como una cosa muy seria. Es un libro que se llama La reinvención de la física en la era de la emergencia, que es de Robert Laughlin, que es uno que ganó el premio Nobel de física, hace... no sé si es del 2005 este premio Nobel (...) Y nosotras tenemos con S. ... un grupo que le llamamos de física cuántica, que es un poco un aggiornamento de todo esto de la New Age, de todos los libros de autoayuda, 
pero como dándole un respaldo más físico ¿̇no? (...) [S.] nos congregó a toda una serie de mujeres de la zona sur [de la ciudad] ¿no? Y nos pasó unas películas, hay una serie de películas de esta gente (...) La primera que vimos fue ¿Qué rayos sabemos? (...)

Y bueno, ocurrió que en esta reunión había una que había sido docente (...) que dijo: ‘bueno, pero nosotros hemos visto una película, todo el mundo quedó muy impactado con esta película, pero -dice- hay que saber qué es la física cuántica’. Mínimamente, aunque sea que te lo expliquen así en un nivel fenomenológico más o menos ¿no cierto? Hay que saber qué es la física cuántica” (2OIO).

Si nos permitimos comprender la lectura desde una perspectiva más abierta, abrimos la puerta para que los lectores y las lectoras nos sorprendan. 


\section{Referencias bibliográficas}

- Acosta Gómez, L. (i989). El lectory la obra: Teoría de la recepción literaria. Madrid: Gredos.

- Bahloul, J. (2002). Lecturas precarias. Estudio sociológico sobre los "poco lectores", trad. de A. Cue. México: Fondo de Cultura Económica. 1998.

- Barthes, R. (1982). Lección inaugural, $\amalg^{\mathrm{a}}$ ed., trad. de O. Terán. En Barthes, R., El placer del texto y Lección inaugural de la cátedra de semiología literaria del Collège de France ( IIII50). México: Siglo XXI. I978.

- Bearingpoint Business Consulting / Esade (2003) Estudios de evolución de indicadores económicos del Sector Editorial I993-200I. Obtenido el i6 de junio de 20 oro desde

http://prensa.esade.es/esade/documentos/estudios/sectoreditorial.pdf. Publicación no periódica en línea.

- Bourdieu, P. (i988). La distinción. Criterios y bases sociales del gusto, traducción de M. C. Ruiz. Madrid: Taurus. I979.

- Bourdieu, P. (I99I). El sentido práctico, trad. de A. Pazos. Madrid: Taurus. I980.

- Boyer, A. M. (2008). Les paralittératures. Paris: Armand Colin.

- Chartier, R. et al.(I999). Cultura escrita, literatura e historia: coacciones transgredidas y libertades restringidas: conversaciones de Roger Chartier con Carlos Aguirre Anaya, Jesús Anay a Rosique, Daniel Goldin y Antonio Saborit, $2^{\mathrm{a}}$ ed. México: Fondo de Cultura Económica.

- Deleuze, G.\& Guattari, F. (I977). Rizoma: Introducción, 2 a ed., trad. de J. Vázquez Pérez y U. Larraceleta. Valencia: Pre-textos. 1976.

- Donnat, O. (2004). Encuestas sobre el comportamiento de lectura. Cuestiones de método, trad. de H. García. En Bernard Lahire (comp.), Sociología de la lectura (59-84). Barcelona: Gedisa.

- Eagleton, T. (1988, 1998). Una introducción a la teoría literaria, 3 a reimpresión, trad.de J. Calderón. México: Fondo de Cultura Económica. I983 ( ${ }^{\mathrm{a}}$ ed.), I996 ( $2^{\mathrm{a}}$ ed., aumentada).

- Eco, U. (1998). Los límites a la interpretación, $2^{\mathrm{a}}$ ed., trad. de H. Lozano. Barcelona: Lumen. I990.

- Eco, U. (2OIO). Internet es idiota, como Funes el memorioso, entrevista. Diario Perfil (p. 4). Buenos Aires, 6 de junio, Suplemento de Cultura. 
- Fernández, M. (2006). Un axolotl con un hombre adentro: saberes literarios de sujetos considerados no lectores. En Fernández, M. \& Ferreiro, E. Lecturas sobre lecturas (pp. 9-33). México: CONACULTA.

- Foucault, M. (i99o). Tecnologías del yo, trad. de M. Allende Salazar. En Tecnologías del yo y otros textos afines (pp. 45-94). Barcelona: Paidós / I.C.E.-U.A.B. I988.

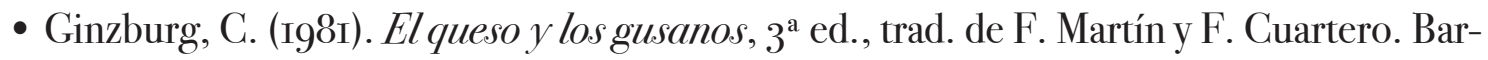
celona: Muchnik. 1976.

- Habermas, J. (I98I). Historia y crítica de la opinión pública: la transformación de la vida pública, trad. de A. Doménech. Barcelona: Gustavo Gili. I962.

- Kalman, J. (2004). El acceso a la cultura escrita: la participación social y la apropiación de conocimientos en eventos cotidianos de lectura y escritura. Revista Mexicana de Investigación Educativa, I7, 37-66.

- Kalman, J. (2008). Discusiones conceptuales en el campo de la cultura escrita. Revista Iberoamericana de Educación, 46, 2008, IO7-I34.

- Kant, I.(I978). Respuesta a la pregunta. ¿Qué es la Ilustración?, 2ª edición, trad. de E. Imaz. En Filosofía de la Historia (pp. 58-67). México: Fondo de Cultura Económica.

- Lacan, J. (2OOI). De una cuestión preliminar a todo tratamiento posible de la psicosis, $8^{\text {a }}$ ed., trad.de T. Segovia. En Escritos, Vol. 2 (pp. 5³-564). Buenos Aires: Siglo XXI. 1966.

- Lahire, B.(2004). Conclusión. Del consumo cultural a las formas dela experiencia literaria, trad. de H. García. En Lahire, B. (comp.) Sociología de la lectura (pp. I79-197). Barcelona: Gedisa.

- Litwin, E.(comp.) (2005). Tecnologías educativas en tiempos de Internet. Buenos Aires: Amorrortu.

- Manguel, A. (2005). Una historia de la lectura. Buenos Aires: Emecé.

- Papalini, V. (2OIO). Géneros de la cultura masiva: entre el verismo y el reencantamiento del mundo. I Foro Editorial de Estudios Hispánicos y Americanistas. Castellón: Universidad de Jaume I.

- Peroni, M. (2003). Historias de lectura. Trayectorias de vida y de lectura, trad. de D. Luz Sánchez. México: Fondo de Cultura Económica. 988.

- Petit, M. (200I). Lecturas: del espacio íntimo al espacio público, $2^{\mathrm{a}}$ reimp., trad. de M. y M. Paleo y D. Luz Sánchez. México: Fondo de Cultura Económica. 
- Poulain, M. (2004). Entre preocupaciones sociales e investigación científica: el desarrollo de sociologías de la lectura en Francia en el siglo XX, trad. de H. García. En Lahire, B. (comp.) Sociología de la lectura (pp. 17-57). Barcelona: Gedisa.

- Rockwell, E. (i995). De huellas, bardas y veredas. En Rockwell, E. (coord.) La escuela cotidiana (pp. 13-57). México: Fondo de Cultura Económica. 